Haemophilus influenzae and Staphylococcus aureus. Opsonisation with ficolin-2 promoted phagocytosis of $P$ aeruginosa (PA01) by human neutrophils in a MASP-2 but not $c 1 q$ dependent manner $(p<0.0001)$ (Abstract T2 figure 1). On multivariable analysis chronic bacterial colonisation $(\mathrm{OR}=3.5 ; \mathrm{p}<0.0001)$ and particularly $P$ aeruginosa colonisation $(\mathrm{OR}=2.8, \mathrm{p}=0.0001)$ were independently associated with ficolin-2 insufficiency. These patients also had more frequent outpatient exacerbations (mean $3.2 / \mathrm{yr}$ vs $2.4 / \mathrm{yr}, \mathrm{p}=0.01$ ) and unscheduled hospital admissions for exacerbations $(\mathrm{OR}=2.3$; $\mathrm{p}<0.0001$ ).

Conclusion Single nucleotide polymorphisms in the ficolin-2 gene affecting serum levels and carbohydrate binding are associated with non-CF bronchiectasis and increase susceptibility to colonisation with $P$ aeruginosa.

\section{T3 MEASURING EOSINOPHIL KINETICS IN HUMANS}

\section{doi:10.1136/thoraxjnl-2011-201054a.3}

${ }^{1} \mathrm{~N}$ Farahi, ${ }^{1} \mathrm{~A} M$ Condliffe, ${ }^{1} \mathrm{~N} R$ Singh, ${ }^{2} \mathrm{~S}$ Heard, ${ }^{1} \mathrm{R} P$ Simmonds, ${ }^{2} \mathrm{C} K$ Solanki, ${ }^{2} \mathrm{~K}$ Solanki, ${ }^{2} \mathrm{~K}$ K Balan, ${ }^{1} \mathrm{~A} M$ Peters, ${ }^{1} \mathrm{E}$ R Chilvers. ${ }^{1}$ University of Cambridge, Cambridge, UK; ${ }^{2}$ Addenbrooke's Hospital, Cambridge, UK

Introduction and Objectives Eosinophils are major cellular effectors of allergic inflammation and represent an important therapeutic target in asthma. While much is understood about the generation and activation of eosinophils, little is known about their intravascular kinetics and physiological fate. The purpose of this study was to image sites of eosinophil distribution and measure eosinophil kinetics in healthy individuals using autologous 111-Indium-labelled eosinophils.

Methods To determine "gold standard" kinetics of minimallymanipulated eosinophils, mixed leucocytes were isolated from the blood of healthy volunteers, labelled with 111-Indium-tropolonate and re-injected. Blood was sampled $0.75-72 \mathrm{~h}$ post-injection. Neutrophils and eosinophils were isolated in parallel, and cell-associated radioactivity was measured. To image sites of eosinophil margination/uptake eosinophils were purified using plasma-Percoll gradients and anti-CD16 immunomagnetic beads, labelled with 111Indium-tropolonate and re-injected. The distribution of eosinophils was recorded by $\gamma$ camera dynamic imaging $(0-40 \mathrm{~min})$ followed by static imaging up to $72 \mathrm{~h}$.

Results Using minimally manipulated granulocytes we found that the $45 \mathrm{~min}$ neutrophil recovery was $57 \pm 10 \%(n=7)$ and the intravascular lifespan was $10.3 \pm 0.1 \mathrm{~h}$, in agreement with previous studies. By contrast, the $45 \mathrm{~min}$ recovery of eosinophils was $15 \pm 2 \%$ $(\mathrm{n}=7)$ and eosinophil lifespan was $25.2 \pm 3.8 \mathrm{~h}$. Moreover, eosinophils appeared to re-circulate at $\sim 4 \mathrm{~h}$ and $9 \mathrm{~h}$ before monoexponential removal. Using 111-Indium-eosinophils and $\gamma$ camera imaging, we demonstrated initial retention of cells in the lungs, clearing to baseline by $40 \mathrm{~min}$, with some early accumulation in the liver and progressive accumulation in the spleen $(n=3)$. Simultaneous blood sampling showed that the $45 \mathrm{~min}$ recovery and intravascular lifespan of purified labelled eosinophils were $11 \pm 2 \%$ and $29.3 \pm 2.1 \mathrm{~h}$, respectively, comparable to minimally manipulated cells. Purified cells also exhibited recirculation at $\sim 6 \mathrm{~h}$ and $12 \mathrm{~h}$. Of note, the disappearance of eosinophils from the liver at $6 \mathrm{~h}$ and $9 \mathrm{~h}$ coincided with their re-appearance in circulating blood, suggesting the liver as a possible site of transient eosinophil sequestration.

Conclusions This work provides the first in vivo measurements of eosinophil kinetics in healthy volunteers. Our data suggest that 111-In-labelled-eosinophils can be used to monitor the organ distribution and fate of eosinophils non-invasively. This technique may have an important role in assessing the therapeutic effects of eosinophil-targeted drugs.

\section{T4 SAFETY AND EXPRESSION OF A SINGLE DOSE OF LIPID- MEDIATED CFTR GENE THERAPY TO THE UPPER AND LOWER AIRWAYS OF PATIENTS WITH CYSTIC FIBROSIS}

doi:10.1136/thoraxjnl-2011-201054a.4

${ }^{1} \mathrm{G}$ Davies, ${ }^{1} \mathrm{~J}$ C Davies, ${ }^{2} \mathrm{D}$ R Gill, ${ }^{2} \mathrm{~S} C \mathrm{Hyde},{ }^{3} \mathrm{C}$ Boyd, ${ }^{3} \mathrm{~J} \mathrm{~A}$ Innes, ${ }^{3} \mathrm{D}$ J Porteous, ${ }^{4} \mathrm{~S}$ H Cheng, ${ }^{4} \mathrm{R}$ K Scheule, ${ }^{5} \mathrm{~T}$ Higgins, ${ }^{1} \mathrm{U}$ Griesenbach, ${ }^{5} \mathrm{E}$ W FW Alton. ${ }^{1}$ Imperial College, London, UK; ${ }^{2}$ University of Oxford, Oxford, UK; ${ }^{3}$ University of Edinburgh, Edinburgh, UK; ${ }^{4}$ Genzyme Corporation, Massachusetts, USA; ${ }^{5}$ Fibrosis Gene Therapy Consortium, UK

Introduction and Objectives We undertook a clinical trial of non-viral CFTR gene therapy assessing safety, dose and transgene expression in preparation for a Multi-dose trial (MDT) designed to assess clinical efficacy.

Methods A single nebulised and/or nasal dose of plasmid CFTR (pGM169)/GL67A was delivered to patients aged $=16$ years with a baseline FEV $1>60 \%$ predicted. Clinical and laboratory parameters were measured at intervals until day 28. A cohort of patients also underwent pre- and post-dosing (day 6 or 14) bronchoscopies for functional (airway potential difference (PD)) and molecular (QRT-PCR) evidence of vectorspecific CFTR expression. Patients receiving a nasal dose underwent brushings for ORT-PCR and serial nasal PD measurements.

Results 35 patients received a nebulised dose of $20 \mathrm{ml}(\mathrm{n}=17), 10 \mathrm{ml}$ $(\mathrm{n}=10)$ or $5 \mathrm{ml}(\mathrm{n}=8)$. A short-lived, dose-related drop in FEV1 was observed over the next $6 \mathrm{~h}$ (mean [SD]: $20 \mathrm{ml} 25.7$ [10.2]\%; $10 \mathrm{ml}$ 17.7 [9.9]\%; $5 \mathrm{ml} 13.0$ [4.4]\% of baseline). Subjects also experienced a systemic inflammatory response which was similarly dose-related and generally limited to the first $24-48 \mathrm{~h}$ post-dosing. A cohort of 6 patients (4@10 ml; 2@5 ml) received4g paracetamol over an 18-h period post-dosing; none of these patients developed a fever. Intriguingly, these subjects also appeared to have reduced systemic inflammatory responses. Molecular (mRNA) evidence of gene transfer was observed in some individuals from upper or lower airway brushings. On lower airway PD measurement, the majority of patients showed an increase towards non-CF values after nebulised gene therapy. 19 patients received a $2 \mathrm{ml}$ nasal dose and 11 $(58 \%)$ had some response in chloride secretion on nasal PD. In the two most positive individuals, responses were within the normal (non-CF) range and persisted to days 63 and 91, respectively.

Conclusions We consider the side effects after $20 \mathrm{ml}$ nebulised dose excessive for repeated application. Those at 10 and $5 \mathrm{ml}$ were more acceptable. Gene expression was confirmed in some patients, and restoration of CFTR function to the non-CF range has been observed out to 13 weeks following a single nasal dose. These data support progression of this agent to MDT.

Funding UK CF Trust.

\section{T5 THE KCa3.1 K+ CHANNEL MEDIATES WOUND HEALING IN HUMAN MYOFIBROBLASTS}

doi:10.1136/thoraxjnl-2011-201054a.5

${ }^{1} \mathrm{~K}$ M Roach, ${ }^{2} \mathrm{~W}$ Coward, ${ }^{3} \mathrm{C}$ Feghali-Bostwick, ${ }^{1} \mathrm{~S} \mathrm{M}$ Duffy, ${ }^{1} \mathrm{P}$ Bradding. ${ }^{1}$ University of Leicester, Leicester, UK; ${ }^{2}$ University of Nottingham, Nottingham, UK; ${ }^{3}$ Department of Medicine, Division of Pulmonary, Allergy, and Critical Care Medicine, University of Pittsburgh, Pittsburgh, Pennsylvania, USA

Idiopathic pulmonary fibrosis (IPF) is a common progressive interstitial lung disease and current treatments are ineffective. The $\mathrm{Ca}^{2+}$-activated $\mathrm{K}^{+}$channel $\mathrm{K}_{\mathrm{Ca}} 3.1$ modulates the activity of several structural and inflammatory cells which play important roles in model diseases characterised by tissue remodelling and fibrosis. We hypothesise that $\mathrm{K}_{\mathrm{Ca}} 3$.1-dependent cell processes are a common denominator in IPF. We have therefore examined $\mathrm{K}_{\mathrm{Ca}} 3.1$ expression and function in human myofibroblasts derived from patients with IPF and non-fibrotic controls (NFC). IPF tissue was obtained from diagnostic lung biopsies, and NFC tissue from healthy lung removed 